\title{
Increasing access to family planning and reproductive health services through community work: A case study of a dual cadre model in India
}

Jaleel Ahmad

Population Council

Isha Bhatnagar

Population Council

M.E. Khan

Population Council

Follow this and additional works at: https://knowledgecommons.popcouncil.org/departments_sbsr-rh

Part of the Health Policy Commons, International Public Health Commons, Maternal and Child Health Commons, Obstetrics and Gynecology Commons, Public Health and Community Nursing Commons, Public Health Education and Promotion Commons, and the Women's Health Commons How does access to this work benefit you? Let us know!

\section{Recommended Citation}

Ahmad, Jaleel, Isha Bhatnagar, and M.E. Khan. 2012. "Increasing access to family planning and reproductive health services through community work: A case study of a dual cadre model in India." New Delhi: Population Council. 


\section{INCREASING ACCESS TO FAMILY PLANNING AND REPRODUCTIVE HEALTH SERVICES THROUGH COMMUNITY HEALTH WORKERS:}

A CASE STUDY OF A DUAL CADRE MODEL IN INDIA

\section{CASE STUDY REPORT}

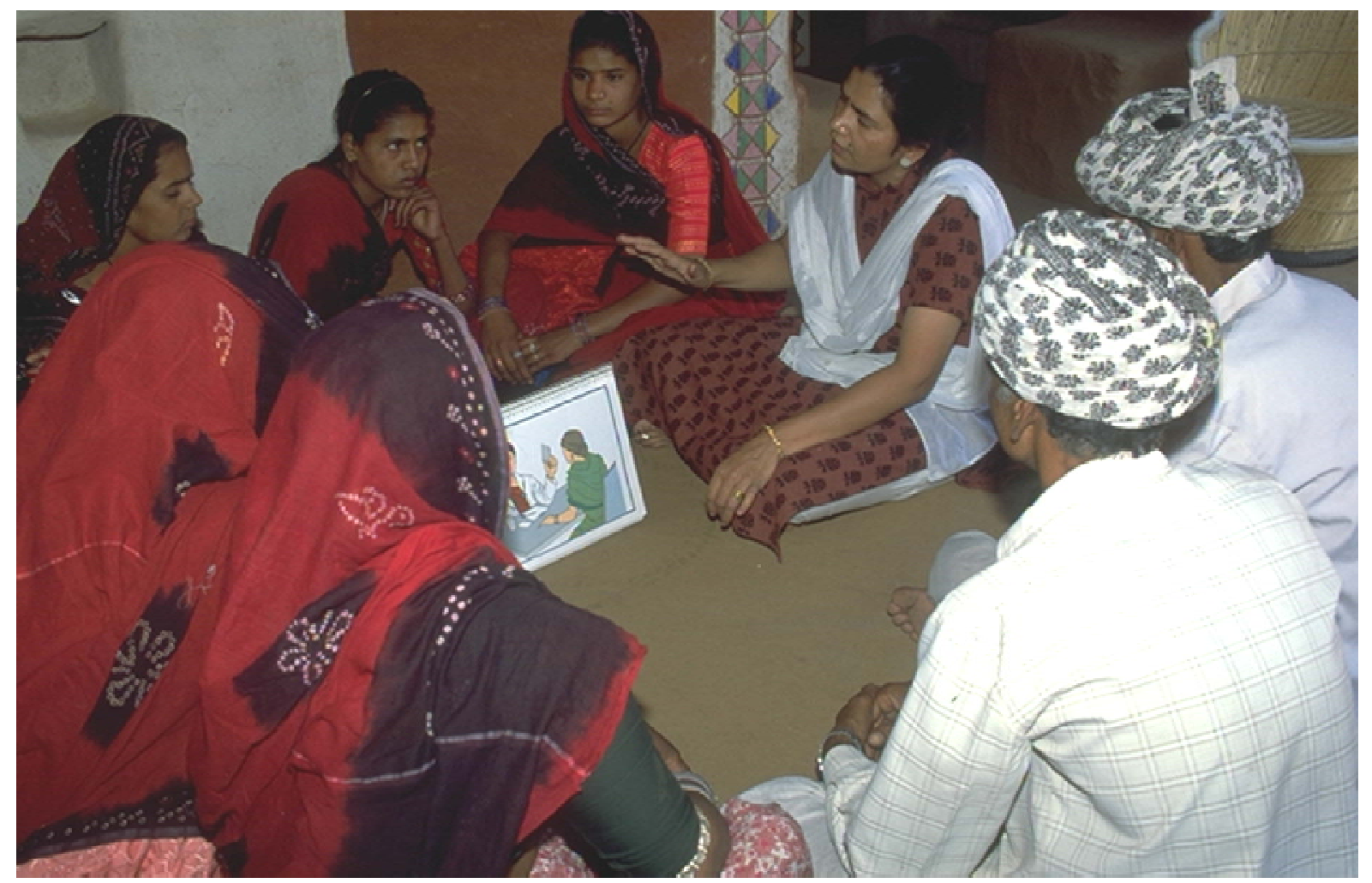

Jaleel Ahmad, Isha Bhatnagar and M.E. Khan 
(C) 2012 The Population Council, Inc.

1 Population Council

The Population Council confronts critical health and developmental issues, from stopping the spread of HIV to improving reproductive health and ensuring that young people lead full and productive lives. Through biomedical, social science, and public health research in 50 countries, we work with our partners to deliver solutions that lead to more effective policies, programs, and technologies that improve lives around the world. Established In 1952 and headquartered in New York and Washington, DC, the Council is a nongovernmental, nonprofit organization governed by an international board of trustees.

www.popcouncil.org

This study is made possible by the generous support of the American people through the United States Agency for International Development (USAID) under the terms of Cooperative Agreement AID-OAA-1000065. The contents do not necessarily reflect the views of USAID or the United States Government.

Jaleel Ahmad, Isha Bhatnagar, M.E. Khan

Population Council, New Delhi, India

Any part of this publication may be photocopied without permission from the publisher, provided that copies are distributed without charge and that full source citation is provided. The Population Council would appreciate receiving a copy of any materials in which the text is used.

\section{Suggested Citation}

Ahmad J, I Bhatnagar and ME Khan. Increasing Access to Family Planning and Reproductive Health Services Through Community Health Workers: A Case Study of a Dual Cadre Model in India. Washington, DC: The Population Council, 2012. 



\section{Acronyms}

$\begin{array}{ll}\text { ANC } & \text { Antenatal Care } \\ \text { ANM } & \text { Auxiliary Nurse Midwife } \\ \text { ASHA } & \text { Accredited Social Health Activist } \\ \text { AWW } & \text { Anganwadi worker } \\ \text { BMGF } & \text { Bill and Melinda Gates Foundation } \\ \text { CHW } & \text { Community Health Worker } \\ \text { CHO } & \text { Community Health Officer } \\ \text { CPR } & \text { Contraceptive Prevalence Rate } \\ \text { FP } & \text { Family Planning } \\ \text { FGD } & \text { Focus Group Discussion } \\ \text { IUCD } & \text { Intrauterine Contraceptive Device } \\ \text { JSY } & \text { Janani Suraksha Yojana program } \\ \text { KII } & \text { Key Informant Interview } \\ \text { MoHFW } & \text { Ministry of Health and Family Welfare } \\ \text { NRHM } & \text { National Rural Health Mission } \\ \text { PC } & \text { Population Council } \\ \text { PI } & \text { Principal Investigator } \\ \text { PNC } & \text { Postnatal Care } \\ \text { UP } & \text { Uttar Pradesh } \\ \text { USAID } & \text { United States Agency for International Development } \\ \end{array}$




\section{Contents}

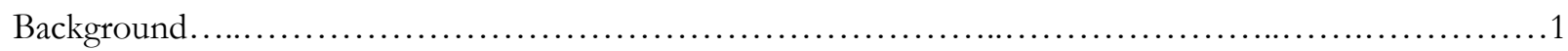

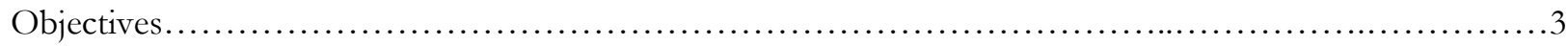

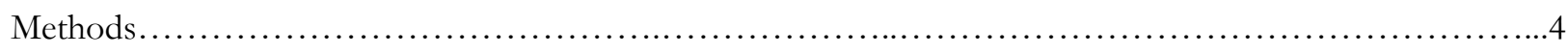

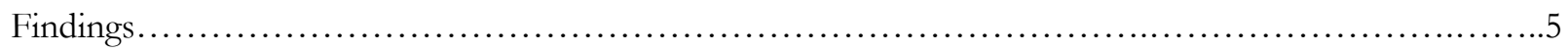

ANM and ASHA Selection and Training.............................................. 5

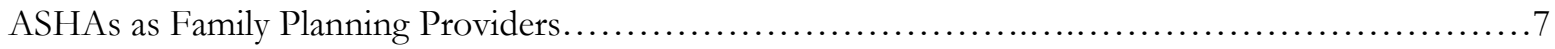

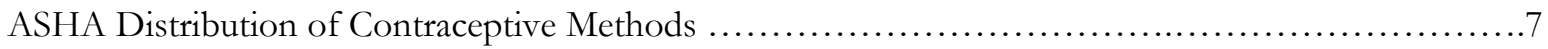

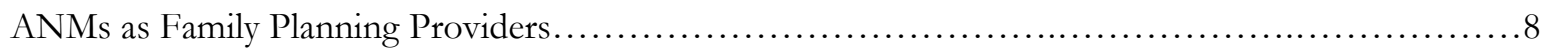

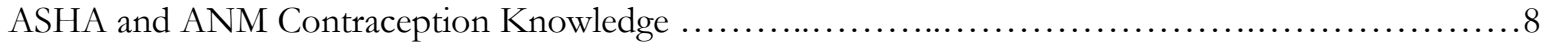

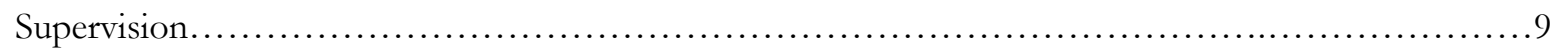

ASHA and ANM Mobile Phone Use for Improved Supervision............................... 10

Discussion, Conclusion, and Recommendations..........................................12

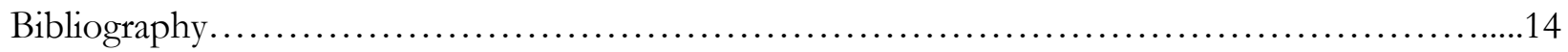




\section{List of Tables}

Table 1: $\quad$ Compensation package for accredited social health activist (ASHA) 2

Table 2: Roles and responsibilities of ASHA and ANM role in relation to ASHA as assigned 3 under NRHM

$\begin{array}{ll}\text { Table 3: } & \text { Training status of ASHA in UP and Bihar }\end{array}$

Table 4: $\quad$ Contraceptives supplied and in stock with ASHAs in UP and Bihar 11

Table 5: Correct responses of health workers regarding various modern spacing methods 12

Table 6: $\quad$ Supervisory roles reported by ANM $(\mathrm{N}=161) \quad 13$

Table 7: Issues discussed in meetings with ANMs as reported by ASHAs, Bihar 2011

Table 8: Job-related use of mobile phones by ANMs and ASHAs (Bihar 2010) 15 


\section{Introduction}

\section{Background}

Integration, and the idea of a service delivery team, have resulted in community health worker (CHW) programs employing more than one level of worker. A community volunteer with minimal training may be responsible for health education and referrals, with a worker with greater training providing services to more than one community (a dual cadre model).

Reviews of CHW programs highlight that CHWs have often convincingly affected program outputs, outcomes, and impacts. One reviewer of CHW programs concludes, "there is robust evidence that CHWs can undertake actions that lead to improved health outcomes ...," while a second commentator observes, "there is no longer any place for discussion of whether CHWs can be key actors in achieving adequate health care" (Lehmann and Sanders 2007; Frankel and Doggett 1992). The same authors also concede, however, many CHWs programs are not successful and call for careful planning and research to identify and combat key problems. "What does emerge is the inescapable conclusion that in almost all areas, CHWs are failing to achieve the contribution which is clearly their potential, and which is an essential pre-condition of health for all."

In India, CHW use is long established. In the early 1960s CHWs provided condoms, contraceptive pills, and promoted early childhood education and nutrition. In 2005, the National Rural Health Mission (NRHM), launched by the Ministry of Health and Family Welfare (MoHFW), introduced the Janani Suraksha Yojana (JSY) program to reduce maternal and neonatal mortality, promoting institutional delivery, postpartum care, and family planning (FP). Under JSY, 800,000 CHWs (one for every 1,000 rural population), called Accredited Social Health Activists (ASHAs), have been trained in states with poor development and health indicators including Rajasthan, Uttar Pradesh, Uttarakhand, Madhya Pradesh, Bihar, Chhattisgarh, Jharkhand, and Orissa. JSY is perhaps one of the largest conditional cash transfer programs, and ASHAs' work as change agents and are crucial links between communities and the health system.

Before the introduction of ASHAs, mid-level Auxiliary Nurse Midwives (ANMs) were responsible for community health education and services such as antenatal care (ANC), delivery, IUCD insertion, and sterilization referrals. Because of ANMs' many job responsibilities, their community health extension work was mostly neglected (Mavalankar and Vora 2010). Under JSY, community extension work and some primary care responsibilities are shifted to ASHAs, who are tasked with identifying pregnant women; facilitating ANC check-ups; motivating women for institutional deliveries during ANC checkups; and organizing child immunization. ASHAs are also expected to counsel women about contraception, especially during the postpartum period; distribute condoms and pills ${ }^{1}$; and refer women for sterilization and IUCDs. ASHAs receive performance-based payments as incentives. Table 1 (page 2) lists ASHAs’ payments for various services.

\footnotetext{
${ }^{1}$ ANMs are supposed to screen women for pill eligibility and subsequently ASHAs are expected to provide the pill.
} 
Table 1: Compensation package for accredited social health activist (ASHA)

\begin{tabular}{|c|c|c|c|}
\hline $\begin{array}{l}\text { Serv. } \\
\text { No. }\end{array}$ & Head of compensation & Amount in Rs. & Amount in \$ \\
\hline \multirow[t]{5}{*}{1} & 3 ANC, 2 TT injection, 100 IFA & 100 & 2.02 \\
\hline & Transportation & 250 & 5.07 \\
\hline & Stay with the client (food) & 150 & 3.04 \\
\hline & Promotion of colostrum feeding within 1 hour and 2 PNC visit & 50 & 1.01 \\
\hline & Newborn care in case of normal delivery (three visits) & 50 & 1.01 \\
\hline 2 & Birth and death registration & 5 & 0.11 \\
\hline \multirow[t]{2}{*}{3} & Motivation for- & 150 & 3.04 \\
\hline & Vasectomy/NSV & 200 & 4.05 \\
\hline \multirow[t]{3}{*}{4} & 1 pack of condom (3 condoms) & 1 & 0.02 \\
\hline & 1 pack of OCP & 1 & 0.02 \\
\hline & 1 dose of ECP & 2 & 0.04 \\
\hline 5 & Immunization session & 150 & 3.04 \\
\hline 6 & Pulse polio day & 75 & 1.52 \\
\hline 7 & $\begin{array}{l}\text { Complete immunization of a child (polio, } 3 \text { doses of DPT, } 1 \text { dose } \\
\text { of measles vaccine) }\end{array}$ & 100 & 2.02 \\
\hline 8 & Organizing Village Health and Nutrition Day (VHND) & 150 & 3.04 \\
\hline 9 & Health awareness meetings in the village & 100 & 2.02 \\
\hline 10 & To maintain village health register and records/year & 500 & 10.1 \\
\hline 11 & Dots & 250 & 5.07 \\
\hline 12 & Household toilet promotion & 75 & 1.52 \\
\hline \multirow[t]{3}{*}{13} & Leprosy detection, referral, confirmation and registration & 100 & 2.02 \\
\hline & - after complete treatment for PB leprosy cases & 200 & 4.05 \\
\hline & - $\quad$ after complete treatment for MB leprosy cases & 400 & 8.11 \\
\hline
\end{tabular}

ANMs now concentrate on clinical activities such as providing ANC, assisting delivery, immunizing children, and inserting IUCDs. In addition, in each village in ANMs' areas, they organize two immunization camps every month. Village ASHAs and Anganwadi workers (AWWs) mobilize the community to bring children for routine immunization. Generally, immunization camps are at the Anganwadi center, which operates under the Integrated Child Development Services (ICDS) program of the Ministry of Women and Child Development. ANMs also supervise ASHAs by verifying the number of services ASHAs provide so ASHAs receive correct payments. ANMs are also expected to make site visits at least twice in a month, on immunization days, to observe and examine ASHAs' work, registers, and stocks of supplies including pills and condoms. On average, an ANM supervises five to eight ASHAs. ANMs' and ASHAs' roles are listed in Table 2 (page 3). 
Table 2: Roles and responsibilities of ANMs and ASHAs assigned by NRHM

\begin{tabular}{|c|c|}
\hline Roles of ANMs & Roles of ASHAs \\
\hline $\begin{array}{l}\text { Guide ASHA in following activities: } \\
\text { - Weekly/fortnightly meetings with ASHAs to discuss } \\
\text { preceding week/fortnight activities; guide ASHA in } \\
\text { case any problems are encountered } \\
\text { - Inform ASHA of date/time of outreach sessions and } \\
\text { also guide her in bringing beneficiaries to sessions } \\
\text { - Participate and guide organizing of AWC Health } \\
\text { Days } \\
\text { - Assist ASHAs in updating eligible couple registration } \\
\text { in villages } \\
\text { - Utilize ASHAs for motivating pregnant women to } \\
\text { travel to subcenters for initial checkups } \\
\text { - Guide ASHAs in bringing married couples to } \\
\text { subcenters for FP adoption } \\
\text { - Guide ASHAs in motivating pregnant women for full } \\
\text { course of IFA Tablets and TT Injections, etc. } \\
\text { - Orient ASHA on pill dose schedule and side effects } \\
\text { - Educate ASHAs on pregnancy and labor warning } \\
\text { signs so ASHAs can identify and help beneficiary get } \\
\text { further treatment } \\
\text { - Inform ASHAs of date, time, place for initial/ } \\
\text { periodic trainings and ensure ASHA TA/DA payment } \\
\text { for attending training, and performance payment }\end{array}$ & $\begin{array}{l}\text { - Identify pregnant woman as JSY } \\
\text { beneficiaries and report and facilitate ANC } \\
\text { registration } \\
\text { - } \quad \text { Assist pregnant woman in necessary } \\
\text { certifications } \\
\text { - } \quad \text { Facilitate at least three ANC check-ups } \\
\text { including TT injections and IFA tablets } \\
\text { - } \quad \text { Promote and facilitate institutional delivery } \\
\text { - } \quad \text { Arrange newborn immunization through } \\
\text { 14 weeks } \\
\text { - Keep mother and child birth and death } \\
\text { records } \\
\text { - Make PNC visits } \\
\text { Mobilize community and facilitate access } \\
\text { of health and health-related services at } \\
\text { Anganwadi/sub-center/primary health } \\
\text { centers, such as immunization, ANC, PNC } \\
\text { check-up, supplementary nutrition, } \\
\text { sanitation, and other services provided by } \\
\text { the government. } \\
\text { Depots for essential supplies: oral } \\
\text { rehydration salts (ORS), iron-folic acid } \\
\text { tablets (IFA), chloroquine, disposable } \\
\text { delivery kits (DDK), pills, condoms, etc. }\end{array}$ \\
\hline
\end{tabular}

Since JSY's inception, several evaluations have revealed that ANC registration and institutional deliveries have improved significantly in almost all focus states, with some improvements also reported for fully immunized child coverage (CORT 2008; DRS 2009; Khan et al. 2010). These studies also reveal, however, that ASHAs do not actively provide contraception information and services, seemingly because condom and pill delivery does not yield performance fees, so ASHAs do not prioritize it (Khan et al. 2010; Khan et al. 2011). Other factors that appear to be associated with poor FP service performance include limited or no supervision by ANMs, and poor training and lack of knowledge about short-acting contraceptive methods (DRS 2009; Khan et al. 2011; Khan et al. 2011). This case study describes and examines how the dual-cadre model of ANMs and ASHAs functions at the community level, for determining mobile phone technology's potential for improving this model's functioning.

\section{Study Objectives}

1. Studying ANMs' and ASHAs' roles;

2. Investigating the two cadres' supervisory relations and other interactions;

3. Determining barriers keeping ASHA contraceptive provision at low levels;

4. Determining whether ASHAs have sufficient FP knowledge to counsel and provide short-acting contraceptive methods;

5. Investigating the potential of mobile phone technology for improving ASHA supervision. 


\section{Methods}

This case study is based largely on secondary analysis of several quantitative and qualitative data sets collected through three recent large-scale Population Council studies in two states in North India-Uttar Pradesh (UP) and Bihar. In addition to secondary analysis of these data sets, key informant interviews (KIIs) specific to this study's objectives were conducted. The data sets are comprised of:

- Shaping Demand and Practices to Improve Family Health Outcomes in Rural Uttar Pradesh, supported by the Bill and Melinda Gates Foundation (BMGF), in which a representative sample of 4,472 currently married women aged 15 to 34 were interviewed, along with 289 ASHAs, 161 ANMs and various stakeholders including staff at 144 government health facilities, with 308 in-depth interviews (IDIs) among other stakeholders including ASHAs, AWWs, and women, complementing the quantitative data.

- Shaping Demand and Practices to Improve Family Health Outcomes in Bihar, supported by BMGF, interviewed 2,941 currently married women aged 15 to 34, along with 212 ASHAs and 137 ANMs, along with 317 stakeholder IDIs.

- A 2011 baseline survey on UP maternal and newborn health by Population Council, supported by BMGF covering 2,000 households, 174 ASHAs, and 115 ANMs (Population Council 2011).

- The 2009-2010 Evaluation of the ASHA Program by the National Health System Resource Center (NHSRC), Ministry of Health and Family Welfare, Government of India, in which data were collected in mixed method approaches using qualitative study, review of secondary data, and a sample survey in eight states in India including UP, with IDIs of program officers, program managers, and some ANMs and ASHAs; sampled respondents included ASHAs (100), beneficiaries (600), ANMs (25), AWWs (100), and representatives of the Panchayati Raj Institution (100) (NHSRC 2011).

- To fill remaining information gaps, Council staff collected additional information from ASHAs and ANMs in IDIs with four ANMs and eight ASHAs, from one block in UP's Meerut district.

- Information on mobile phone use is from a Population Council study, Pattern of Mobile Phone Use Among the Health Care Providers, in which 46 ASHAs and 30 ANMs in 48 villages were interviewed as part of a review of CHWs introduced through JSY (i.e. ASHAs) (Khan et al. 2011).

In this case study, the framework suggested by Foreit and Raifman has been used, which identifies six critical factors in successful CHW program implementation: program organization; FP and other services provided by CHWs; worker training and supervision; supply and material availability; worker selection and training; and community involvement. 


\section{Findings}

The dual cadre model of the Indian health system was created under a major reproductive and child health flagship program, the National Rural Health Mission (NRHM), in 2005. NRHM's focus is providing special attention to rural health, particularly in selected economically disadvantaged states with high maternal and neo-natal mortality and heavy disease burden. Many innovative concepts were introduced, including planning decentralization at primary health center (PHC) and district levels, enhancing resource allocation to all levels of the health sector, and providing unrestricted funds at all levels-subcenter, PHC, district, state-so immediate needs or innovative initiatives could be attended to. A conditional cash transfer component was introduced, both for consumers, for institutional delivery at public health facilities, and for providers (ASHAs), for educating and motivating pregnant women to adopt healthy behaviors directly affecting survival of mother and newborn, including FP promotion (Table 2).

ASHAs, introduced as the new staff cadre, were conceptualized as volunteers, selected by community leaders and health system-trained to link communities and the health system. According to NRHM guidelines, ASHAs should be female residents of constituent villages, either married, widowed, or divorced, and preferably, from 25 to 45 years old. ASHAs should be literate, with formal education to the eighth standard. ASHAs should receive minimum training of 23 days, over a period of 12 months. Payment for ASHA's work is based on performance (suggested payments for various activities are listed in Table 1).

ASHAs' major roles are promoting institutional delivery, under Janani Suraksha Yojana (JSY), and community mobilization. ANMs, who had many of these community extension responsibilities, are asked to spend more time on clinical services such as conducting deliveries, ANC checkups, child immunization, basic treatment, and organizing village health and sanitation days. ANMs are also responsible for supporting and supervising ASHA activities. (ASHA functions and ANMs' supervisory roles, per Government of India's program, are listed in Table 2.)

For further supportive supervision, NRHM recommends, for every 10 ASHAs, one community mobilizer should be appointed who, along with the ANM, provides supportive supervision to ASHAs and gives practical guidance on community mobilization. In many states, including UP, no such appointments have yet been made, and all responsibility for supervising ASHAs lies with ANMs.

The dual cadre program was well conceived by NRHM and provided all necessarily resources, organizational support, and monitoring inputs for effective implementation, but implementation has varied vastly across different states.

\section{ASHA and ANM Selection and Training}

\section{ASHA selection}

NRHM has provided clear guidelines for ASHA selection, which is expected to be facilitated by community leaders. The selection procedure begins with a village meeting, then shortlisting a number of candidates from which Gram Sabba (village leadership) selects the final candidate, who is then endorsed by the Gram Panchayat (elected local leaders governing village affairs) and forwarded to the relevant health authority. ASHA selection criteria specified in national guidelines are:

\section{ASHA selection criteria}

- One ASHA per 1,000 population

- A married woman, primary resident of constituent village, and preferably between 25 and 45 years

- Effective communication skills, leadership qualities, and ability to reach community

- Literate, with formal schooling to eighth standard (may be relaxed if no suitable candidate with this qualification is available)

- Adequate representation from disadvantaged groups should be ensured, for serving those groups 
Thus, the selection procedure involves the community and is expected to select the most eligible women desiring to serve their communities. Various reports on JSY show, however, the guidance was not followed strictly; often Panchayat leadership or other influential villagers selected preferred candidates from their families, caste, or those of relatives. Disadvantaged groups, scheduled castes, or minorities are rarely selected, partly because they lack a resource network, and partly due to their lesser education; many have not passed the eighth standard, while more privileged groups provide many such candidates. The latest JSY evaluation, in 2011 by NHSRC, in eight states, declares:

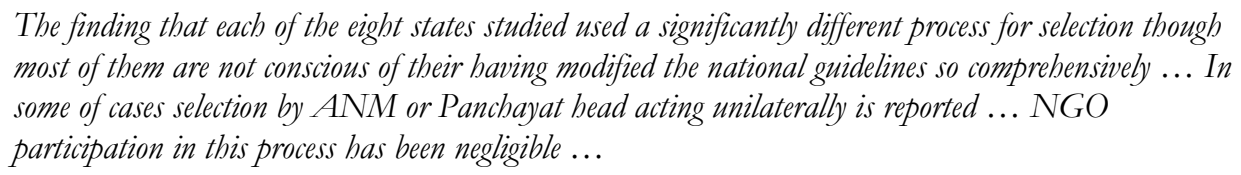

At its conclusion, however, the report states that many fears of poor selection, or compromised by caste or economic consideration, as major impediments to program implementation are not borne out. Population Council's studies in UP and Bihar, however, provide evidence, because of expectation ASHAs (like ICDS workers) will, in the long run, become regular Health Department staff, that most ASHAs were selected from influential groups, with very few from scheduled castes or minority populations. Scheduled caste and minority females repeatedly mentioned that ASHAs did not provide them services, because of ASHAs belonging to higher castes, or rich or influential families. According to the UP and Bihar studies, half of pregnant women were not contacted by ASHAs, because those pregnant women are from disadvantaged groups; this scenario illustrates the difficulties of impartial ASHA selection.

\section{Training}

ANMs are the paramedic cadre of the Indian public health system, technically trained in nursing and midwifery in an 18-month course. Six months of the course is practical training, during which a trainee is attached to a hospital or PHC. ANMs are responsible for providing services at a sub-center, the lowest level health facility in rural areas, serving populations of 5,000, or they are attached to a PHC. Under the NRHM program, ANMs now undergo 23-day refresher training in skilled birth attendance (SBA) focusing on practical skills for managing different aspects of delivery, recognizing early stage complications, and if required, referring women to a higher level facilities.

ASHAs are initially trained in five different health modules, for 23 days, for as much as 12 months (Table 3). The ASHA's main role is educational, promoting health behaviors including institutional delivery, and accompanying women to clinics for delivery. Studies show, however, ASHA training is far from complete. Although almost all (97\%) ASHAs report some training, levels varied. For example, while twothirds of ASHAs were trained in four or more modules, one-third were trained in three or less, and nine percent were trained in one only. This variable training is also reflected in days of training for different ASHAs in UP and Bihar (Table 3). The training standard was much worse in Bihar, where 87 percent of ASHAs were trained for only 10 days, or less, instead of the required 23 days (NHSRC 2011).

Table 3: ASHA training status in UP and Bihar

\begin{tabular}{ccc}
\hline $\begin{array}{c}\text { Trained } \\
\text { (No. of days) }\end{array}$ & $\begin{array}{c}\text { UP }(2009) \\
(\mathrm{N}=289)\end{array}$ & $\begin{array}{c}\text { Bihar }(2011) \\
(\mathrm{N}=200)\end{array}$ \\
\hline $1-10$ & 31.5 & 87.1 \\
$11-15$ & 16.3 & 10.2 \\
$16-21$ & 46.4 & 0.0 \\
$21+$ & 5.9 & 0.0 \\
\hline
\end{tabular}

NHSRC's ASHA program evaluation also identified poor training as a key limiting factor:

One of the main weakness in the training program is the content of the training modules—especially of training module 2 -which covers a wide number of vitally important topics in too incomplete and superficial a manner and does not even have a trainer guidebook accompanying it. The training module design has a weak understanding of competency based training. [NHSRC 2011] 


\section{ASHAs as Family Planning Providers}

Although ASHAs have increased ANC visits, institutional deliveries, and child immunization, they have made little positive impact on FP (NHSRC 2011). A Population Council study in UP shows modern contraceptive method use, from 2005, when JSY was introduced, to the end of 2009, when the study was concluded, increased from 20 percent to 28 percent, about eight percent in four years (Khan et al. 2011). Given the fact UP's CPR increased, on average, 1.5 percent annually even before JSY's introduction, an additional annual increase of half a percent is modest. In Bihar, the situation is also poor, where postpartum contraception increased from 13 percent in 2005-06 to 20 percent in 2010-11, seven percent in five years, the same as the prior contraception increase in Bihar (Khan et al. 2011).

Both studies indicate JSY has not made noticeable difference in CPR, particularly in spacing methods, for which ASHAs are not paid. This is partly due to JSY's primary focus on maternal and newborn health; strengthening FP delivery services is only marginally addressed by a fee for counseling and sterilization education. Recently, however, MoHFW has decided ASHAs will be the primary depositories of pills, condoms, and ECPs, and that these methods will not be available free from any other public rural facility. As a service fee, ASHAs have been allowed to charge Rs.1, for each pack of condoms and pills, and Rs.2, for one pill of ECP. In UP as well as Bihar, many ASHAs questioned the absence of a fee for their time for providing spacing methods. This is perhaps one of the reasons that ASHAs did not perceive contraception counseling and promotion as their responsibility, as well as promoting postpartum contraception for healthy spacing; only five percent in UP and 10 percent in Bihar reported counseling and education on FP as a responsibility.

These findings are supported by a large national evaluation by MoHFW in 2011, in which ASHAs did not mention FP as one of their 13 most frequent activities in the six months prior to the survey. During indepth interviews in the 2009 UP study, many women reported no counseling by an ASHA on contraception after delivery:

'The ASHA has never told me [about contraception]... I don't want more children, but my husband does not want to use condoms and forces me [for sex]. He has told me about Mala-D [contraceptive pill], but I don't use them, as my sister-in-law told me that they do not work." [Female, UP 2009]

"My husband told me to get condoms from the ASHA, but I have not asked her till now because her house is at a distance, and I have not gone there for any work, nor has she visited us. The ASHA does not distribute contraceptive methods nor give advice on contraceptive use. But if we get condoms, my husband will use them." [Female, UP 2009]

"When ASHA had come few months ago to give polio vaccination, then I had asked for Nirodh [brand of condoms], but till now she has not given it to me." [Female, UP 2009]

"ASHA has not advised me on family planning after my last delivery. I and my busband do not use anything, any contraceptive method, because he feels shy in buying a condom from the shop. So what do we do?" [Female, UP 2009]

\section{ASHA Distribution of Contraceptive Methods}

ASHAs are expected to stock and distribute condoms and contraceptive pills, along with pregnancy kits, ORS packets, and other items. Data from the UP and Bihar studies show that 55 to 83 percent of ASHAs were, at some point, supplied with condoms, and 37 to 76 percent were supplied with pills, at some point. On the day of the interview, however, few ASHAs had any contraceptive methods in stock (Table 4); the situation was better in UP than Bihar.

The NHSRC report, however, shows ASHAs do counsel women on sterilization, for which referral payments are made to ASHAs. About 50 percent of ASHAs were successful in referring more than one female sterilization per month in the six month period preceding the survey (NHSRC 2011, page 63). 
Table 4: Contraceptives supplied and in stock with ASHAs in UP and Bihar

\begin{tabular}{lcccc}
\hline \multirow{2}{*}{ FP methods } & \multicolumn{2}{c}{ UP study (2011) } & \multicolumn{2}{c}{ Bihar study (2011) } \\
\cline { 2 - 5 } & Ever supplied & Available in stock & Ever supplied & Available in stock \\
\hline Condom & 82.8 & 55.2 & 54.7 & 18.9 \\
Pills & 75.9 & 35.1 & 36.8 & 10.8 \\
ECP & 5.7 & 2.9 & 3.3 & 2.4 \\
\hline \multicolumn{1}{c}{ Total ASHAs } & 174 & $\mathbf{1 7 4}$ & $\mathbf{2 1 2}$ & $\mathbf{2 1 2}$ \\
\hline
\end{tabular}

\section{ANMs as Family Planning Providers}

Before NRHM, ANMs were expected to provide both curative and preventive community care. Responsible for basic health care services in rural areas for up to 5,000 people, ANMs provided delivery care, mother and child immunization, and common illness treatment. ANMs were also responsible for information and communication (IEC) activities on health issues, including FP. Currently, ANMs' preventive services have been shifted to ASHAs. Apart from curative health services, ANMs' FP role, along with ASHAs, is FP method counseling and replenishing ASHA contraceptive supplies (condoms, OCP and ECP).

Interviews with 10 ANMs, as part of this study, explored their FP role, with three main reasons offered for their lack of interest in counseling about short-acting contraceptive methods:

- They perceive low demand for contraceptives: "Most of the men get condoms from the market, and very few women require contraceptive methods from us." [ANM, UP 2011]

- They perceive that condom and pill delivery is not a JSY priority: "If the government wanted to promote these methods, they could have paid some incentives like they do for promoting IUD and male and female sterilization ... We have hardly been asked during monthly meetings about statistics on condom distribution, or why the performance for condom/pills is not good, as in the case of pregnancy registration or three ANC." [ANM, UP 2011]

- Only sterilization activities are routinely discussed during supervisory visits: "In our PHC meetings, we have to report number [of] ANC done, number of institutional deliveries in our areas, and number of children covered in immunization ... We have to report number [of] women motivated for sterilization.” [ANM, UP 2011]

\section{ASHA and ANM Contraception Knowledge}

The 2011 Bihar study assessed ASHA and ANM knowledge of various contraceptive methods, and while their contraceptive method awareness was very high, correct knowledge of spacing methods was inadequate. Of 212 ASHAs interviewed, only 57 percent knew that IUDs could be inserted within six weeks after delivery; only 13 percent knew that a mother must wait six months after delivery to start oral contraceptives; and only 45 percent knew that a pill should be taken as soon as possible if a woman missed a pill. With the exception of pill's correct start after delivery, ANMs were only marginally more knowledgeable than ASHAs (Table 5).

Table 5: Correct health worker responses for various modern spacing methods

\begin{tabular}{lcc}
\hline Correct knowledge & ANM & ASHA \\
\hline All three conditions of LAM & 6.6 & 9.4 \\
IUD can be inserted within 6 weeks* after delivery & 60.5 & 56.6 \\
OCs can be started after 6 months of delivery & 38.7 & 13.2 \\
A pill should be taken as soon as possible if it is missed & 43.8 & 45.3 \\
Mean number of years for which an IUD could be used & 6.05 & - \\
\hline Total & 137 & 212 \\
\hline
\end{tabular}

*Includes few correct answers of within 2 days by trained provider 


\section{Supervision}

ANMs not only supervise ASHAs, review their records, and verify and approving ASHAs' financial claims, but they also help educate those women ASHAs are unable to convince, through health issue counseling (Table 2, for ANM supervisory role details). In monthly ASHA meetings at PHCs, each ANM reviews the work of their supervised six to eight ASHAs and refills ASHAs' medical kit supplies, including condoms and pills.

The 2009 UP study indicates, in general, except for reviewing payment records, ANMs do not perceive ASHA supervision to be a key responsibility: When asked to list their key roles, only 28 of 161 (17\%) ANMs mentioned it (Table 6).

Table 6: Supervisory roles reported by ANM $(\mathbf{N}=161)$

\begin{tabular}{lc}
\hline Roles & Percent \\
\hline Monitoring ASHAs' work & 17 \\
Asking ASHAs to motivate women for ANC & 73 \\
Asking ASHAs to discuss ANC with families & 37 \\
Supervising ASHA work in promoting JSY & 44 \\
\hline
\end{tabular}

Note: Percentage may not add up to 100 due to multiple responses, Source Population Council (2009)

ANM supervision of ASHAs is largely limited to administrative issues such as verification and payments, with little or no assistance in problem solving, on-the-job training, or other supportive supervision. Much of this is due to the fact the two cadres have limited contact, with two regular contacts at vaccination camps twice a month and at monthly meetings at PHCs. On these occasions, both are occupied with other duties - vaccination or administrative work — with little time for supervisory activities or performance review, other than for services for which ASHAs are paid. As Table 7 indicates, only 17 percent of ASHAs in Bihar reported FP performance discussions in these meetings. The study also reported that only 11 percent of ASHAs mentioned FP performance discussions with supervisors.

Table 7: Issues discussed in meetings with ANMs, reported by ASHAs, Bihar 2011

\begin{tabular}{lc}
\hline Issues discussed in the meetings (N=212) & Percent \\
\hline MCH issues (Wellbeing of pregnant women, Nischay kit/Muskan) & 71.1 \\
Child care (advice related to ORS) & 1.0 \\
Immunization and pulse polio & 62.3 \\
Family planning & 17.0 \\
Other health issues (TB, HIV/AIDS, etc.) & 14.6 \\
Water and sanitation & 2.8 \\
Wellbeing of girl child & 2.8 \\
Administrative issues & 14.6 \\
\hline
\end{tabular}

Note: Percentage may not add up to 100 due to multiple responses, Source Population Council 2011

The qualitative studies in UP (2009) and Bihar (2010) complement these observations. ASHA interviews revealed that ANMs and ASHAs usually meet twice a month, providing ANMs limited chances for support and supervision:

"The ANM does not visit our village regularly ... We meet only during immunization sessions and do not get a chance to discuss anything ... I only take belp of the ANM in filling immunization register..." [ASHA, UP 2009]

"I meet the ANM on every Wednesday and Saturday at the sub-center on MCH and immunization day. She comes on time and gives injections to women and children, what other help do we expect from her?"

[ASHA, UP 2009] 
"I get a chance to meet the ANM twice in a month on immunization day and we only work together for immunization ...” [ASHA, UP 2009]

"The ANM primarily helps me update my register on immunization of children, that's all the support I get from her.” [ASHA, Bihar 2010]

"The ANM and I work together on immunization day, which happens on the third Saturday of each month. I also meet her at the PHC, for monthly meetings. I also help her during delivery if she needs a cloth to clean or wipe the baby. The ANM does not help me in any way." [ASHA, UP 2009]

"I meet ANM once a month during immunization day in village. Other than that I meet her when I take a sterilization or institutional delivery to the PHC." [ASHA, UP 2009]

Both the UP and Bihar studies show limited supervision and coordination, particularly for FP:

"The ANM had given me a stock of OCPs and condoms. Now they have finished and the ANM has not supplied me anymore." [ASHA, Bihar 2010]

"I don't stock contraceptives since the ANM keeps them. People who need them ask her."

[ASHA, Bihar 2010]

"I tell women to have OCPs during the night after dinner and if possible with milk so that it does not make them feel hot as they say. I give OCPs to those women who ask for it, the rest of the women know that the ANM stocks it and can directly approach her and take OCPs from here. If I run out of stock, I take more from the ANM when I go to the PHC to take an institutional delivery case."

[ASHA, UP 2009]

\section{ASHA and ANM Mobile Phone Use for Improved Supervision}

A study in Bihar on mobile phone use showed that 97 percent of ANMs and doctors, and 70 percent of ASHAs, own a mobile phone (many ASHAs who do not own a phone reported access, to one owned by a husband or other family member); 86 percent of ASHAs reported client use of mobile phones, for ASHA guidance on health-related issues (Khan et al. 2011). Ninety-three (93) percent of ASHAs reported seeking ANM guidance from a mobile phone, and 77 percent reported using the phone for instructions from their supervisors.

The Bihar study included questions for both ASHAs and ANMs about their mobile phone ownership and use for work. Their answers are presented in Table 9:

Table 9: Job-related mobile phone use by ANMs and ASHAs, Bihar 2010

\begin{tabular}{lc}
\hline Purpose & Percent \\
\hline Contacting supervisors & 46.2 \\
Contacting clients & 41.5 \\
To talk with relatives living in other cities & 22.3 \\
\hline Total & 130 \\
\hline
\end{tabular}

Qualitative data from the UP (2009) and Bihar (2010) studies corroborates these observations:

"I do not have a mobile. I use my busband's mobile to speak to ANM and patients when I come back from the CHC after admitting a patient for delivery I use mobile to know her status."

[ASHA, UP 2009]

"The last time I used the mobile phone was to contact the ANM to ask her whether she was present at the facility as I was bringing her a delivery case." [ASHA, Bihar 2010] 
"People of the community call me up (on my mobile phone) to tell me when the woman has started labor so I can take her to the facility for delivery. Whenever I take a woman to the PHC for delivery I use my mobile phone to inform the ANM in advance that I am coming with a delivery case."

[ASHA, UP 2009]

"I use the mobile phone to talk to the doctor/ ANM and find out when my check (of the incentive) has been released. I also enquire if the JSY checks of the women of my community have been released. The mobile phone has helped me stay in contact with the PHC so I don't have to go there again and again for any task." [ASHA, UP 2009]

"I call the ANM to know when the next immunization session will be beld." [ASHA, Bihar 2010]

"The PHC doctor sends me a text message (SMS) to inform about the meetings to be beld at the PHC." [ASHA, UP 2009]

"When the ANM comes for ANC she examines pregnant women and if any one of them has any problems she prescribes a medicine. After the ANM leaves she asks me to stay in contact with the women and communicate to her about women's condition through the mobile phone and she also advise me to follow up these cases for pregnancy care and how long the medication should continue. I talk to the ANM 4-5 times a month by mobile phone." [ASHA, Bihar 2010]

"The ANM calls me up to tell me when she has come at the sub-center. It helps me know when to go there or bring children and pregnant women to the sub-center for check-up As ANM now does not go bouse to house and she coordinate with me for mobilizing the clients." [ASHA, UP, 2009]

"The ANM calls me if I am late for the immunization session." [ASHA, Bihar 2010]

"I take help from the ANM by calling her and asking which all children have not received their vaccination on the due date. The ANM tells me who have missed out, so it is easy for me to call those children (from their homes) to come for immunization." [ASHA, Bihar 2010]

"Yes, I have a mobile with good network, I talk with my relatives, pregnant women and ANM, and I can read SMS but cannot write/ type them. If a SMS is sent in Hindi then I can read it and will communicate the message to the community." [ASHA, UP 2009]

Some ASHAs expressed willingness to disseminate health information to clients if they receive messages on mobile phones:

"If I receive bealth SMS in Hindi then I will read them and spread the message to others in the community." [ASHA, UP 2009] 


\section{Discussion, Conclusion, and Recommendations}

Establishing dual worker cadres in India by shifting community extension tasks from ANMs to local ASHAs, as part of the NRHM and JSY programs, has been well conceived. Task shifting allows ANMs, as trained paramedics, to devote more time to clinical work and ASHA supervision and guidance, and in principle, this scheme best utilizes available human resources. Today, there are more than 825,000 ASHAs, and each ANM is expected to supervise and guide between six and eight ASHAs.

All six critical elements hypothesized for a successful CHW program in the conceptual framework guiding this case study (strong organizational support, community participation, selection, training, supervision, and supplies) have been well planned by NRHM. The ASHA is conceived as a link between the community and health sector, and full community participation, endorsed by the Panchayat (local governance), in ASHA selection is recommended, and well-defined selection criteria have been provided by the Government. Similarly, by linking ASHA payment to task performance, the government has tried to make the program sustainable. A well-defined schema for supervision and guidance by ANMs (and community mobilizers), drug kit provision for each ASHA, and adequate resource allocation for supplies and training, are important components of JSY's success. For standardizing ASHA training-for a total of 23 days and seven training modules - clear guidelines have been provided. Thus, the program is well conceived and designed, with NRHM endeavoring to make ASHAs community and the health sector links for promoting healthy practices, particularly those affecting maternal and newborn survival.

This study, based on available literature, reports, and additional qualitative data, shows wide variations in the program's implementation. Many of NRHM's rules and guidelines were violated or misinterpreted. As a result, disadvantaged groups have, largely, been poorly represented and neglected by ASHAs, and civil society participation, particularly by NGOs, has been ignored in the selection procedure.

The two weakest aspects of the present JSY program are poor ASHA training and their lack of supervision and guidance. The present study, as well as a 2011 evaluation of ASHAs by NHSRC, clearly underlines the lack of competency-based training for ASHAs. According to the NHSRC analysis, not only the training itself, but the modules developed for training fail to cover topics comprehensively: "The weakness of the first four modules is that in almost every topic information is incomplete and insufficient for the ASHA to undertake any action, even referral action." Population Council's studies in UP and Bihar also support this. Evidence shows CHWs lack correct contraceptive method knowledge and often share the same misconceptions and myths about methods as community members. CHWs have not been given adequate training or counseling aids to educate couples in their community on FP. ASHA training is taken much more seriously in Bihar, however, where an ASHA resource center coordinates ASHA activities including training, supplies, and supervision, and ASHA training is outsourced to 19 NGOs with competency-based criteria for training certification.

In states such as UP and Bihar, general governance is a major problem, and the ASHA initiative suffers as a result. NRHM plans for ANMs and community mobilizers to share responsibility for supervising and guiding ASHAs' work, but the UP government has decided not to hire community mobilizers, while Bihar has hired a block-level community mobilizer. As a result, complete responsibility for ASHA supervision now lies with ANMs. This study shows that supervision by ANMs is confined to routine checks of ASHAs' registers, along with administrative procedures such as supply provision and endorsement performancebased payments. The qualitative study reveals ANMs lack supervisory skills, and have no checklists for focusing and standardizing their ASHA supervision and guidance. It is critical ANMs take the role of guiding ASHAs in the field and depending on the availability of time, they make joint visits to families.

Most ASHAs, except in Bihar, have received drug kits, but this study clearly shows supply replenishment to be a major challenge (NRSRC 2011). The Council's studies in UP and Bihar also reveal that condoms and pills were out of stock, in half or more cases in UP and more than two thirds of cases in Bihar; ECPs were almost completely absent in both. The contraceptive supply situation of ASHAs is not necessarily because methods are in short supply at PHCs, or with ANMs, but is often because of ASHAs' lack of interest in educating couples on contraception. ASHAs do not consider FP as a primary activity, and hence, if contraceptive methods are out of stock, it does not make any difference to them.

In terms of policy, ASHAs' principal role was conceived as promoting institutional delivery, facilitating ANC/PNC, and mobilizing communities for child immunization. Most ASHAs reported availability of ORS in their stock. With the recent change of policy designating ASHA as sole health system distributors 
of pills, condoms and ECPs, withdrawing free supplies from all public facilities in rural areas, the situation is expected to change significantly, and these methods should be readily available from ASHAs.

This study shows, while JSY and rural dual cadre worker availability has potential for an educational campaign for increasing FP use among couples, three critical components are missing. First, at the policy level, there is a lack of emphasis on the fact that one of ASHAs' key roles should be promoting all contraceptive methods, to meet couples' RH needs and help them adopt health birth spacing. So far, at the policy level, ASHAs are employed for promoting ANC checkups, institutional delivery, and community mobilization for immunization. Counseling and information dissemination by ASHAs, for bringing about behavior change, with direct bearing on family health, should be recognized, and their role should be broadened. Increasing ASHAs' roles can happen only at policy level, particularly in states, where these requirements are implemented. With recent policy change ASHAs have been made the sole depositories for pills, condoms, and ECP, which may help broaden ASHAs' roles, while focusing them on family health.

Second, competency-based training and strengthening knowledge and counseling skills among ASHAs for promoting contraception is limited. In 233 districts of India, ASHAs are sole depositories for contraceptive methods, but they have a very limited knowledge of them, particularly ECP. It is critically important to monitor information provided by ASHAs to women, and whether they impart correct usage information for contraceptive methods, particularly for ECP, for which they receive Rs.2 for selling one pill compared to Rs.1 for selling one pack of three condoms or pill cycle.

Third, supportive supervision is a major, missing link in efficient ASHA functioning. ANMs do not perceive ASHA supervision, mentoring, and guidance as an important responsibility. Further, ANMs themselves lack supervisory skills. To address this, perceptions of district authorities, as well as MOICs of PHCs, have to change so ASHAs are key health sector functionaries, and their work can be monitored. Unless the perception of the importance of ASHAs, and the need to support and guide them changes, ANMs may not take their supervisory roles seriously. Further, ANMs also need supervisory skill development and a checklist to make supervision systematic.

Finally, this study also shows that mobile phone ownership and/or access by ANMs and ASHAs is almost universal, and in one study, mobile phones were regularly used by health workers for supervision, information dissemination, and client interaction. OR is needed for exploring mobile phone use in supportive supervision strengthening and continuing education of ASHAs and ANMs. 


\section{Bibliography}

Center for Operation Research and Training (CORT). 2008. Assessment of Janani Suraksha Yojana in Uttar Pradesh. Vadodra, India: Sponsored by UNICEF New Delhi.

Development Research Services (DRS). 2009. Current evaluation of Janani Suraksha Yojana in Uttar Pradesh, Unpublished report. Delhi: DRS.

Foreit J.R. and S. Raifman. 2011. Increasing Access to Family Planning (FP) and Reproductive Health (RH) Services Through Task-sharing Between Community Health Workers (CHWs) and Community Mid-level Professionals in Large-scale Public-sector Programs: A Literature Review to Help Guide Case Studies. New York: Population Council.

Frankel S. and M.A. Doggett. 1992. The Community Health Worker: Effective Programmes for Developing Countries. London: Oxford University Press.

Khan M.E., A. Hazra and I. Bhatnagar. 2010. Impact of JSY on selected target behaviour in rural UP. Journal of Family Welfare 56.

Khan M.E., G.I. Darmstadt, U.K. Tarigopula and D. Ganju. 2011. Shaping Demand and Practices to Improve Family Health Outcomes in Bihar. New Delhi: The Population Council.

Khan M.E., G.I. Darmstadt, U.K. Tarigopala and D. Ganju. 2011. Shaping Demand and Practices to Improve Family Health Outcomes: Designing a Behavior Change Communication Strategy in Rural Uttar Pradesh. New Delhi: The Population Council.

Lehmann U., and D. Sanders. 2007. Community Health Workers: What Do We Know About Them? Geneva: World Health Organization.

Mavalankar D. and K.S. Vora. 2010. The Changing Role of Auxiliary Nurse Midwife (ANM) in India: Implications for Maternal and Child Health (MCH). Working Papers: 2755, eSocialSciences.

Ministry of Health and Family Welfare. Guidelines on Accredited Social Health Activists (ASHAs). http://mohfw.nic.in/NRHM/RCH/guidelines/ASHA guidelines.pdf

National Health Systems Resource Centre (NHSRC). 2011. ASHAs: Which Way Forward Evaluation of ASHAs Programme. New Delhi: NHSRC.

Population Council. 2011. Improving Maternal and Neo-natal Health in Northern: A Report. New Delhi: The Population Council. 


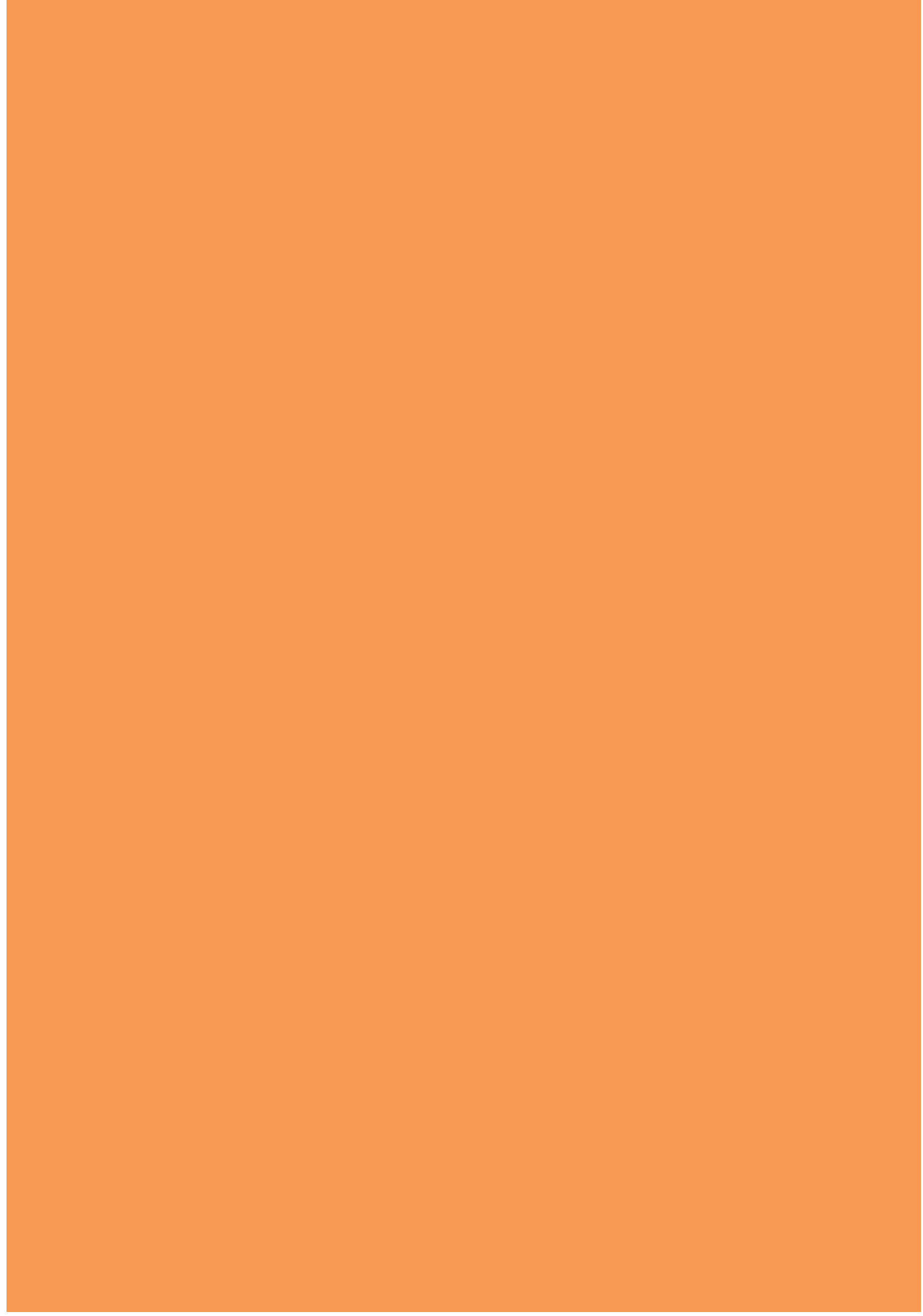

